\title{
Free to Flow? \\ New Results on Capital Mobility amongst the Developed Countries
}

\author{
Rita Madarassy* \\ University of California, Santa Cruz \\ and \\ Menzie Chinn ${ }^{* *}$ \\ University of California, Santa Cruz \\ and NBER
}

August 2002

\begin{abstract}
This paper evaluates the evidence for uncovered and real interest parity at the long horizons for the non-G7 economies. We examine the behavior of exchange rates and interest differentials for bonds with 5-year maturity. Although there are substantial differences in the results among countries, the majority of the countries' interest differentials have correctly signed coefficients, which contrasts strongly with previous studies and provide empirical support for market integration. Similarly, tests of real interest parity indicate a higher degree of equalization. In summary, we find greater evidence of capital and goods market integration than has been found using short term data, indicating that capital market integration has proceeded further even among the smaller developed economies.
\end{abstract}

JEL: F21, F31, F42

Keywords: capital mobility, uncovered interest parity, real interest parity

Acknowledgements: We thank Alina Carare and Hali Edison for providing data. This paper is based on Chapter 1 of Madarassy's Ph.D. dissertation. Chinn acknowledges the financial support of faculty research funds of the University of California.

* Corresponding Author: Santa Cruz Center for International Economics, Department of Economics, Social Sciences I, University of California, Santa Cruz, CA 95064. Tel: (510) 486 2346; Fax: (831) 459-5900; Email: ritam@ucscalumni.com.

** National Bureau of Economic Research, 1050 Massachusetts Avenue, Cambridge, MA 02138. Tel/Fax: (617) 868-3900/2742. Email: chinn@cats.ucsc.edu . 


\section{Introduction}

An observer unacquainted with the empirical literature on capital market integration would be surprised to find that, in this era of talk of globalization, there is little consensus on the degree to which capital is free to move. Partly, the discord arises from differing views on what constitutes capital market integration. However, if one takes some plain vanilla definitions from the international finance literature, the impression one takes away from a survey of the econometric literature is that integration has a long way to go before it is complete.

To make this point more concrete, consider two popular views - uncovered interest parity and real interest parity. The former pertains to financial capital market integration, and posits that in the absence of substantial differences in the way returns on government bonds covary with other macroeconomic variables, interest rates in common currency terms should be equalized. The enormous literature on forward rate bias demonstrates that this condition does not usually hold, even in recent periods. ${ }^{1}$

Real interest parity pertains to mobility of physical capital. Here too, the evidence is not terribly supportive. If there is more integration among markets then one would expect a freer flow of capital across borders to where ever it may earn the highest rate of return. As a result, one should observe real interest rate equalization among those countries that are more liberalized.

\footnotetext{
${ }^{1}$ See Engel (1996), Froot and Thaler (1990), Frankel and Froot (1990), McCallum (1992), de Brouwer (1995), Moosa and Bhatti (1997), Franchot (1996), Fase and Vlaar (1998).
} 
In this study, we take up these issues for several non-G7 countries. In addition, we augment the standard analysis by examining these parity conditions at long horizons. This project is of interest because there have been few systematic analyses of these countries in recent years. Of course, there are a plethora of studies on the G-7 currencies; most recently, Meredith and Chinn (1998) and Fujii and Chinn (2001) have demonstrated greater evidence for market integration at the longer horizons. However, it is likely that the extent of integration is greatest for these countries, and we anticipate that degree of integration along this dimension is less pronounced for the non-G7. First, their currencies are not traded as much as some of the other major currencies, such as the US dollar, the Yen, and Deutschemark. Second, we anticipate that the long horizon results previously documented might not apply as strongly here, as the corresponding government bonds are more likely to be treated as imperfect substitutes for those of the G7 countries.

To anticipate the results, our findings do differ from results reported in the previous literature, in that the coefficient in the long term for uncovered interest parity and real interest parity regressions are closer to unity. However, they do fall short somewhat of results for the G7 countries. Hence our findings confirm the view of increased - but still limited - financial and goods market integration in some of the smaller developed economies.

The outline of the paper is as follows. Section 2 outlines tests for uncovered interest parity (UIP) and reports the empirical results. Section 3 conducts a similar exercise for real interest parity (RIP). Section 4 concludes. 


\section{Financial Capital Mobility}

\subsection{Theoretical background}

Covered interest parity indicates that the gap between the current spot rate and the forward rate will equal the interest differential between assets measured in local currencies, assuming the debt instruments are of equal default risk, as long as risk-free arbitrage can take place. This covered interest parity condition can be expressed:

$$
f_{t, t+k}-s_{t}=\left(i_{t, k}-i_{t, k}^{*}\right)
$$

Where $s_{t}$ is the log spot exchange rate (in terms of the the price of foreign currency in local currency at time $\mathrm{t}), f_{t, t+k}$, is the log forward rate at time $\mathrm{k}$ periods hence, and $i_{t, k}$ is the yield on a bond with maturity of k-periods. ${ }^{2}$

If holding a currency involves risk then it will need to pay a premium to induce investors to hold. Thus the forward rate can be different from the future spot exchange rate by that risk premium, which can be expressed as:

$$
f_{t, t+k}=s_{t, t+k}^{e}+\rho_{t, t+k}
$$

where $\rho$ is an exchange risk premium. Combining the above two equations, one obtains:

$$
s_{t, t+k}^{e}-s_{t}=\left(i_{t, k}-i_{t, k}^{*}\right)-\rho_{t, t+k}
$$

\footnotetext{
${ }^{2}$ Equation (1) is a log approximation to the true parity condition. In all the empirical estimations, we will test the precise parity conditions.
} 
Equation (3) states that the change in the expected k-period spot exchange rate equals the current interest differential between comparable k-period interest earning local currency denominated instruments plus a risk premium.

The uncovered interest parity (UIP) condition refers to the above statement less the risk premium. There are a number of ways that we can test this hypothesis. Since we do not observe expected spot exchange rates, one must make some assumptions in order to proceed further.

Assuming that market participants make mean zero errors in prediction is one way of overcoming the problem of non-observable expected exchange rates; this approach is popularly called the rational expectations methodology. ${ }^{3}$ In this case, the actual, or ex post spot exchange rate will equal the expected spot exchange rate plus an uncorrelated error term:

$$
s_{t+k}=s_{r, t+k}^{e}+\varepsilon_{t, t+k}
$$

Substituting (4) into (3) one obtains (5) below:

$$
s_{t, t+k}-s_{t}=\left(i_{t}^{k}-i_{t}^{k^{*}}\right)+\varepsilon_{t+k}
$$

\footnotetext{
${ }^{3}$ Obviously, this operationalization is only appropriate when the economy is in a steady state, such that all agents know the structure of the economy. Agents might have rational expectations, but have to learn about the (changing) structure of the economy; in this instance, it may be the case that market expectation errors are not mean zero iid errors. Froot and Frankel (1989) adopt a third route - to use survey data to measure market expectations. In this case, we do not have access to the appropriate data to assess UIP at all the horizons we wish to (e.g., at 5 year horizon).
} 
which can be tested in the regression framework,

$$
s_{t, t+k}-s_{t}=\alpha+\beta\left(i_{t}^{k}-i_{t}^{k^{*}}\right)+\varepsilon_{t+k} \quad H_{o}: \begin{aligned}
& \alpha=0 \\
& \beta=1
\end{aligned}
$$

The null hypothesis, $\mathrm{H}_{0}$, is the maintained UIP condition. The error term here contains expectation errors. Under the alternative, it also contains the risk premia.

An alternative approach is to model the spot exchange using time series methods, and use the estimated equation to forecast the future spot rate. These predictions can then be substituted in for expected spot exchange rate. Since we have little faith in such procedures as applied to exchange rates, we will only implement the ex post methodology for the UIP tests. $^{4}$

The combination of UIP and the rational expectations methodology (what Frankel terms the forward rate unbiasedness hypothesis) has been examined by a number of economists but most have found little support for this version of UIP. Most of the tests are using short term interest rates, or the equivalent forward rates, and typically researchers cannot find evidence in support of the interest rate parity condition. For instance, Froot and Frankel (1990), Froot and Thaler (1990), McCallum (1992), de Brouwer (1995) report large and negative values for the slope coefficient. These results can arise for a number of reasons, including the presence of an exchange risk premium, biased expectations due to either irrationality or learning.

\footnotetext{
${ }^{4}$ Spot exchange rates appear to follow close to a martingale process. Hence, this would imply any resulting predictions of expected changes would be zero - thus reducing the UIP test to one of interest rate equality.
} 
Recently a number of studies have argued that UIP is more likely to hold at long horizons, as over such spans, interest rate and exchange rate movements are more influenced by the fundamentals -- such as inflation and output -- rather than other factors, such as herding behavior, shocks to risk premia and monetary policy. If these are the same factors that cause tests of UIP to fail in the short run, then it may prove useful to examine these conditions at longer horizons.

Awad and Goodwin (1998), Meredith and Chinn (1998), Alexius (2001) have found more support for long horizon interest parity than earlier papers examining the G7 countries. This paper provides further evidence of uncovered interest parity over long horizons for other developed economies.

\subsection{Data and estimation}

We examine the following non-G7 developed countries: Denmark, Finland, Ireland, Norway, Netherlands, Spain, Sweden and Switzerland. The short term interest rate data are obtained from Datastream, and are end-of-period. The long term data are obtained from the Bank of International Settlements database. Data are available monthly from January 1973 to May 1998, and are converted to quarterly frequency using the observation on the last month of each quarter. Hence, all the results reported below pertain to regressions on data at the quarterly frequency. The base sample period for each country is between 1973:1 and 1998:1. (Greater detail on data definitions and sources can be found in Appendix 1.)

Note that for the long horizon regressions, where $\mathrm{k}=20$, one has the problem of overlapping forecasts. This in turn means that even under the null of iid forecasts errors, the regression error will have serial correlation of order MA(k-1). To account for this serial 
correlation, we report robust standard errors using a Bartlett kernel and truncation lag of 19

for 5-year horizon. ${ }^{5}$ The length of the interest rate data available for analysis varies between countries. Moreover, ex post regressions require observations on actually realized exchange rate changes. Hence, the last observation on a five year interest rate one can apply a regression to is in 1996.

\subsection{UIP Results}

Table 1 reports results of UIP regressions at the 3 month horizon. As is clear, the slope coefficients are far from unity predicted by UIP/rational expectations. Of these, the Australian dollar (-1.21), Belgian franc (-1.10) and the Dutch guilder (-1.28) stand out as negative and significantly different from one. There are a number of coefficients that are also negative (Austrian schilling, Norwegian krone) but fail to reject the null hypothesis of $\beta=1$ because of extremely large standard errors. Finally, the point estimates for the Irish pound and the Swedish krona are far away from the posited value, although positive. Only the Finnish markka, Spanish peseta and Swiss Franc have point estimates in excess of unity (the Swiss franc possesses an anomalously large constant, thus making it likely it would reject a joint test).

Tables 2 reports the results of the UIP regressions at the 5 year horizon. The Norwegian krone stands out as the regression reports negative coefficients at long horizons also, so by these criteria there is little capital mobility. On the other hand, the Dutch guilder

\footnotetext{
${ }^{5}$ Estimation is implemented in TSP. The robust errors are generated in the GMM procedure using the ROBUST option.
} 
has a positive slope estimate at long horizon, in contrast to those at the short horizon. Specifically, the Dutch guilder, the 3 month horizon coefficient is -1.28 , while the 5 year horizon coefficient is 0.833 and cannot reject null of unity. Similarly, Sweden also has a positive coefficient three times larger than for the short horizon. The beta coefficient for Switzerland is statistically equal to unity with a smaller standard error than for the short horizon. In the case of Denmark, the coefficient for the long horizon is large, close to unity but the null can be rejected. More support for capital mobility is found at a longer horizon for Netherlands and Sweden, for both of the beta coefficients increase with horizon length.

Unfortunately, we are hampered in making more comparisons due to data availability. That is, we have insufficiently long time series for Belgium, Finland and Spain for long horizon regressions in order to compare against the short horizon estimates, while we do not have short horizon data for Denmark. Another important constraint on our analysis is that the sample periods for short and long horizon results are not conformable due to data availability restrictions, and the fact that ex post realizations are necessary. At the long horizon, the ex post requirement truncates the sample at the recent end of the sample. Thus the Norway krone results pertain to 3 month interest rates over the 1993:2-2000:3 period, and 5 year interest rates over the 1986:1-94:2 period.

In findings similar to those obtained here, Alexius (2001) reports that uncovered interest parity holds better at long than short horizons for 13 OECD countries, including several examined in this study. While the two sets of results are not strictly comparable, as her sample encompasses the last decade and a half of the Bretton Woods era, it is notable that our slope coefficients - estimated over only the more recent floating rate period -- are 
uniformly closer to the posited value of unity than the corresponding point estimates she obtains.

\section{Real Capital Mobility}

\subsection{Theoretical background}

If we further assume that not only that UIP holds, (5) with the risk premium zero, but also that there is equalization of expected returns in the goods market, that is, relative purchasing power parity (equation 7) holds as well,

$$
s_{t, t+k}^{e}-s_{t}=\left(p_{t, t+k}^{e}-p_{t}\right)-\left(p_{t, t+k}^{* e}-p_{t}^{*}\right)
$$

where $\mathrm{p}$ is the log price level. We can rewrite these assumptions to represent the real interest parity condition, recognizing that the $\log$ difference of $\mathrm{p}$ is $\pi$.

$$
\begin{aligned}
& i_{t}^{k}-\pi_{t, t+k}^{e}=i_{t}^{*_{k}}-\pi_{t, t+k}^{*_{e}} \\
& r_{t}^{e k}=r_{t}^{*_{e k}}
\end{aligned}
$$

Equation (8) is the real interest parity condition; it suggests that ex ante, or expected, real interest rates are equalized if UIP and relative PPP hold. Since the expected real interest rates are not observed, one has two alternatives. The first is to use the rational expectations methodology, substituting ex post values as we did in the tests of UIP above, or to model inflation to generate ex ante measures of inflation and hence generate ex ante real interest rates. In both cases, we estimate the regression: 


$$
r_{t}^{e k}=\alpha^{\prime}+\beta^{\prime} r_{t}^{* e k}+\varepsilon_{t+k}^{\prime}
$$

Over short horizons, RIP does not hold much better than UIP. Hodrick (1979), Cumby and Obstfeld (1984), carry out bilateral tests of ex ante real interest rates in the US and other OECD countries. Their results are inconsistent with RIP, and they thus reject real interest rate equalization except in the case of US dollar-Deutsche mark exchange rate. Mishkin (1984) strongly rejects the RIP using short term real interest rates for 7 OECD countries. Cumby and Mishkin (1986) do find some positive relationship between the real exchange rate and the real interest rates, while they can find little support for it they cannot confirm the RIP hypothesis. Unlike the other results, Dutton (1993) provides supporting evidence of RIP when she uses prices that only contain traded goods.

Over the longer horizon there is mixed, but greater, evidence in favor of the RIP theory. Breedon, Henry, and Williams (1999) search for evidence of market integration measured by long term real interest rate convergence and conclude that there is no one global interest rate. In contrast, Ong, Clements, and Izan (1999) and Fujii and Chinn (2001) provide evidence of greater real interest rate covariation at longer horizons.

\subsection{Data and estimation}

The consumer and the producer price indices (CPI and PPI, respectively) are obtained from the International Monetary Fund's International Financial Statistics. In the tests of RIP using ex post real interest rates, the inflation rate corresponding to horizon is used. To generate the ex ante, or expected, inflation series, the quarterly inflation rate is modeled 
using an ARMA specification. The specification is selected using the Schwarz Bayesian information criteria (SBIC), applied to data over the entire sample. The optimal model is used to generate forecast series with a rolling method. That is, after each estimation, the parameter estimates are updated, forecasts generated, the sample window moved up one period, and then the process is repeated until all observations have been exhausted. This procedure generates a set of dynamic forecasts that, at time t, uses a subset of the information available to agents at time t. The selected models for the spot exchange rates are reported in Appendix 2. Once the k-period inflation rates are forecasted, they are used to generate the real interest rate measure in equation (9) above. ${ }^{6}$

\subsection{Results}

Table 3 reports the results for the 3 month horizon, using ex post real interest rates (with a CPI deflator). In line with most previous results, one finds that most of the slope coefficients are small or negative and significantly different from the predicted value of unity.

In contrast, regressions using 5 year ex post CPI deflated real interest rates (Table 4) yield larger coefficients closer to unity, although some point estimates remain negative. These results, however, are sensitive to the choice of deflator. Table 5 reports the results using ex post values of PPI inflation rate to convert nominal rates to real. In this case, more

\footnotetext{
${ }^{6}$ Since this is a two-stage-estimation with a predicted variable in the right hand side the standard errors generate by OLS are neither consistent nor efficient, as explained by McKenzie and McAleer (1997). Hence, we use a generalized method of moments procedure to obtain our estimates.
} 
than half coefficients are positive, and more than half of them are statistically indistinguishable from unity. The results are mostly robust to changes in instrumental variables. In particular, for the Dutch guilder, the Norwegian krone and Swiss franc, both sets of instrumental variables yield slope coefficients that fail to reject the null of real interest parity. One interpretation of this pattern is that in countries with large divergences between tradables and nontradables prices, PPI's may better reflect the price of tradable goods that are relevant to calculating the return on physical capital.

One drawback of the long horizon regressions with ex post real rates is the diminished size of the sample, and the fact that the regression results do not reflect recent patterns in the most recent of the time series observations. Tables 6 and 7 address this issue by using real interest rates calculated using forecasted interest rates. To make this distinction concrete, consider for instance using ex post data; in that case we only have 5 year's worth of data for the Dutch guilder for the 1986:2-93:4 sample, while using forecasted inflation extends that the sample to $1998: 1$.

One notable feature of the results in Table 6 is that all of the coefficients, except for Netherlands, are positive with at least one of the sets of instruments (even when the number of estimates have risen from six to eight). Once again, using a PPI deflator instead of a CPI deflator changes the results somewhat. The most noticeable difference is that the Dutch guilder slope coefficient is now positive and also insignificantly different from unity, regardless of the instrument set used. The Swedish krona coefficient also moves closer to unity, and now cannot reject the null that it equals unity, when lagged quarterly inflation rates are the instrumental variables. In both cases, the Swiss franc does not reject the $\beta=1$ null. 
The long horizon results are largely consistent with our priors, to the extent that the countries that are considered more open and free of capital controls, such as Switzerland, have significant $\beta$ 's closer to unity. In contrast, some countries classified as closed by Frankel (1991) - such as Spain in his examination of the data up to the late 1980's - have lower coefficients.

How do these results compare to previous ones for the G7 countries? Fujii and Chinn (2001) examine the G7 currencies against the US dollar, and consider 3-month, 5-year, and 10-year horizons and conclude that real interest parity appears to hold better at long than short horizons. Specifically, their most informative results are based upon forecasted PPI inflation; all of the long maturity estimates for Germany and Japan exhibit slope coefficients statistically indistinguishable from unity. In the case of the UK, RIP holds at the 5 year horizon. For purposes of comparison, we report UIP and RIP regression results in Table 8 for these the UK pound and Deutsche mark. As in Fujii and Chinn, these results are consistent with UIP and RIP holding; to the extent that we find more mixed results for our set of countries, we can conclude that capital mobility is somewhat less pronounced for the developed economies examined in this study. ${ }^{7}$

\footnotetext{
${ }^{7}$ Regressions results using Jorion (1996) methodology indicate that RIP does not hold, which is consistent with the fact that most of the time the point estimate in the RIP regressions is less than one. Jorion (1996) test for RIP by regressing real interest differentials on the nominal interest rates differentials, where the slope coefficient reveals information about the forecasting ability of the nominal interest differentials with respect to future real differentials, thus a value of beta significantly different from zero suggests that it contains information, or that the real interest rates are not equal.
} 


\section{Conclusions}

Unlike numerous previous studies, this analysis provides greater support for uncovered interest parity combined with unbiased expectations, and the real interest parity condition, for a set of countries less intensively investigated. We confirm the view that there is more evidence in favor of financial and goods market integration at longer horizons than at shorter horizons. ${ }^{8}$ However, the results are by no means unanimous, and indeed while the coefficient estimates are more often positive - in accord with theory - they are also often substantially less than the predicted value of unity. At the long horizon, these coefficients appear to be somewhat lower than those obtained for the G7 economies, suggesting that the degree of integration may vary from group to group.

This last comparison suggests that it would be useful to assess the time variation in the degree of integration more closely, and perhaps link breaks in coefficient estimates with detailed information on institutional and regulatory features of the respective bond markets. We reserve these issues for future research.

\footnotetext{
${ }^{8}$ In line with results in Meredith and Chinn (1998), Alexius (2001) for long horizon UIP and Ong, Clements, and Izan (1999), Fujii and Chinn (2001) for long horizon RIP.
} 


\section{References}

Alexius, A. (2001), "Uncovered Interest Parity Revisited," Review of International Economics, 9(3), 505-517.

Awad, M. and B. Goodwin (1998), "Dynamic linkages among real interest rates in international capital markets," Journal of International Money and Finance, 17, 881907.

Breedon, F., B. Henry, G.Williams (1999), "Long-term Real Interest Rates: Evidence on the Global Capital Market, Oxford Review of Economic Policy, 15(2), 128-142.

Cumby, R.E. and F.S. Mishkin (1986), "The international linkage of real interest rates: the European-US connection," Journal of International Money and Finance, 5, 5-23.

Cumby, R.E. and M. Obstfeld (1984), "International Interest Rate and Price Level Linkages under Flexible Exchange Rates," in Exchange Rate Theory and Practice, ed. by J.F.O. Bilson and R.C. Marston, University of Chicago, Chicago.

de Brouwer, G. (1995), "The Liberalisation and Integration of Domestic Financial Markets in Western Pacific Economies," Australia-Japan Research Centre, Australian National University, mimeo.

Dutton, M.M. (1993), "Real interest parity: new measures and tests," Journal of International Money and Finance, 12, 62-77.

Engel, C. (1996), "The Forward Discount Anomaly and the Risk Premium: A Survey of Recent Evidence," Journal of Empirical Finance, 3, 123-92.

Fase, M. M. G., P.J.G. Vlaar (1998), "International Convergence of Capital Market Interest Rates," De Economist, 146(2), 257-269.

Franchot, A. (1996), "A reexamination of the uncovered interest rate parity hypothesis," Journal of International Money and Finance, 15(3), 419-437.

Frankel, J.A. (1991), "Quantifying International Capital Mobility in the 1980s," in B. D. Bernheim and J. B. Shoven (eds.) National Saving and Economic Performance (Chicago: University of Chicago Press), 227-260.

Frankel, J.A. and K.A. Froot (1990), "Exchange Rate Forecasting techniques, survey data, and implications for the foreign exchange market," NBER Working paper 3470.

Froot K.A. and R.H. Thaler (1990), “Anomalies: Foreign Exchange,” Journal of Economic Perspectives, 4, 179-92. 
Fujii E., and M. Chinn, (2001), "Fin de Siecle Real Interest Parity," Review of International Economics, 11(3), 289-308.

Hodrick, R.J. (1979), "Some Evidence on the Equality of Expected Real Interest Rates across Countries," Working Paper 8-79-80, Graduate School of Industrial Administration, Carnegie-Mellon University.

Jorion, P. (1996), "Does Real Interest Parity Hold at Longer Maturities?" Journal of International Economics, 40, 105-126.

McCallum, B. (1992), "A Reconsideration of the Uncovered Interest Parity Relationship," NBER Working Paper 4113.

McKenzie, C.R., and M. McAleer (1997), "On Efficient Estimation and Correct Inference in Models with Generated Regressors: A General Approach," The Japanese Economic Review. 48(4), 368-389.

Meredith, G., M. Chinn (1998), "Long-Horizon Uncovered Interest Rate Parity," NBER Working Paper 6797.

Mishkin, F.S. (1984), "Are real interest rates equal across countries: an empirical investigation of international parity conditions," Journal of Finance, 39, 1345-1357.

Moosa, I., and R. Bhatti (1997), International Parity Conditions: Theory, Econometric Testing and Empirical Evidence, New York: St. Martin's Press.

Ong, L., K. Clements, H.Y.Izan (1999), "The world real interest rate: stochastic index number perspectives," Journal of International Money and Finance, 18, 225-249. 


\section{Appendix 1: Data Description}

1. 5-year government bond rates: These are the end-of-month (when available) yields on outstanding central government bonds of 5-year maturity converted to quarterly frequency. Source: Bank of International Settlements.

Finland, yield, second mkt., central govt bonds, 10 years mo.-end

Sweden, yield at issue, central govt. bonds, up to 7 years, mo.-end

Belgium, yield, second mkt., govt. bonds over 5 yrs remaining mat., mo.-end

Swiss confederation bonds, mo-end

Spain, yield, second mkt., govt bonds, 5 years, mo.-average

Netherlands, yield, second mkt., central govt. bonds, 5-8 years, mo.-end

Norway, yield, second mkt., govt bonds, 5 years, mo.-average

Sweden, yield, second mkt., central govt. bonds, 5 years, m-end -disc.

2. 3- \& 6-month government bonds and interbank interest rates.

Source: Datastream

Australia treas note 90 days - middle rate

Austria vibor 3 month - offered rate

Belgium treasury bill 6 month - middle rate

Finland interbank close 3 month - middle rate

Ireland interbank 3 month - offered rate

Netherland interbank $3 \mathrm{mth}$ - middle rate

Norway interbank 3 month - offered rate

Spain interbank 3 month - middle rate

Sweden com/bk dep. $3 \mathrm{~m}$ 'dead' - middle rate, Switzerland com/bk dep. 3m 'dead' middle rate

3. Exchange rates: These are end-of-period market or official exchange rates from the IMF's International Financial Statistics database.

4. Inflation: Consumer and producer price indices are obtained from the International Financial Statistics database (IMF). 


\section{Appendix 2:}

Table A-1: The Selected Model Specification for the Quarterly Inflation Series (CPI and PPI)

\begin{tabular}{lcc}
\hline & CPI Inflation & PPI Inflation \\
\hline Australia & $\operatorname{ARMA}(1,1)$ & $\operatorname{ARMA}(1,1)$ \\
Austria & $\operatorname{MA}(1)$ & $\operatorname{AR}(1)$ \\
Denmark & $\operatorname{ARMA}(1,1)$ & $\operatorname{AR}(1)$ \\
Finland & $\operatorname{ARMA}(1,1)$ & $\operatorname{AR}(1)$ \\
Ireland & $\operatorname{ARMA}(1,1)$ & $\operatorname{ARMA}(3,2)$ \\
Netherlands & $\operatorname{ARMA}(1,1)$ & $\operatorname{ARMA}(1,1)$ \\
Norway & $\operatorname{ARMA}(4,1)$ & $\operatorname{AR}(1)$ \\
Spain & $\operatorname{ARMA}(1,2)$ & $\operatorname{MA}(1)$ \\
Sweden & $\operatorname{ARMA}(1,1)$ & $\operatorname{AR}(1)$ \\
Switzerland & $\operatorname{ARMA}(1,1)$ & $\operatorname{AR}(3)$ \\
US & $\operatorname{ARMA}(3,1)$ & \\
\hline
\end{tabular}

Notes: The model specification is selected using the Schwarz-Bayesian criteria (minimum value). The inflation series reject the unit root hypothesis using the ADF test. 
Table 1: 3-month Horizon Uncovered Interest Parity Results

\begin{tabular}{|c|c|c|c|}
\hline & & $\hat{\alpha}$ & $\hat{\beta}$ \\
\hline Austrian schilling & $\begin{array}{c}1991: 2-1998: 3 \\
(30)\end{array}$ & $\begin{array}{l}0.025 \\
(0.038)\end{array}$ & $\begin{array}{l}-1.260 \\
(1.938)\end{array}$ \\
\hline Australian dollar & $\begin{array}{c}1982: 3-2000: 3 \\
(73)\end{array}$ & $\begin{array}{l}-0.048 \\
(0.031)\end{array}$ & $\begin{array}{l}-1.211 * * * \\
(0.743)\end{array}$ \\
\hline Belgian frank & $\begin{array}{c}1985: 1-1998: 2 \\
(54)\end{array}$ & $\begin{array}{l}0.048 \\
(0.032)\end{array}$ & $\begin{array}{l}-1.095^{*} \\
(1.187)\end{array}$ \\
\hline Denmark krone & - & - & - \\
\hline Finnish markka & $\begin{array}{c}1992: 2-1998: 3 \\
(26)\end{array}$ & $\begin{array}{l}0.018 \\
(0.041)\end{array}$ & $\begin{array}{l}2.214 \\
(1.253)\end{array}$ \\
\hline Irish pound & $\begin{array}{c}1984: 1-1998: 3 \\
(59)\end{array}$ & $\begin{array}{l}0.055 \\
(0.044)\end{array}$ & $\begin{array}{l}0.384 \\
(1.405)\end{array}$ \\
\hline Netherlands gulden & $\begin{array}{c}1979: 1-1998: 3 \\
(79)\end{array}$ & $\begin{array}{l}0.041 \\
(0.031)\end{array}$ & $\begin{array}{l}-1.279^{*} \\
(1.355)\end{array}$ \\
\hline Norway krone & $\begin{array}{c}1993: 2-2000: 3 \\
(30)\end{array}$ & $\begin{array}{l}-0.026 \\
(0.029)\end{array}$ & $\begin{array}{l}-0.907 \\
(1.830)\end{array}$ \\
\hline Spanish peseta & $\begin{array}{c}1991: 4-1998: 3 \\
(28)\end{array}$ & $\begin{array}{l}0.036 \\
(0.047)\end{array}$ & $\begin{array}{l}1.840 \\
(1.205)\end{array}$ \\
\hline Sweden krona & $\begin{array}{c}1983: 4-1993: 4 \\
(41)\end{array}$ & $\begin{array}{l}0.031 \\
(0.048)\end{array}$ & $\begin{array}{l}0.249 \\
(1.621)\end{array}$ \\
\hline Swiss franc & $\begin{array}{c}1983: 4-1993: 4 \\
(41)\end{array}$ & $\begin{array}{l}0.150 \\
(0.121)\end{array}$ & $\begin{array}{l}1.260 \\
(3.428)\end{array}$ \\
\hline
\end{tabular}

The sample period pertains to interest rate sample period. Number of observations measured by the number of quarters is in parentheses. Beginning date is the beginning of the interest rate data and ending date is the last observed ex post or forecasted exchange rate minus 1 quarter or the last interest rate data, whichever is earlier. The third and fourth columns are the t-test for alpha $=0$ and beta $=1 . \quad{ }^{*},{ }^{* *},{ }^{* * *}$ indicates coefficient different from null at $10 \%, 5 \%, 1 \%$ significance level respectively. Standard errors are in parentheses. For Belgium, 6-month changes in exchange rates are regressed on the 6-month interest rates. 
Table 2: 5-Year Horizon Uncovered Interest Parity Results with Ex Post Spot Exchange Rates

\begin{tabular}{lccc}
\hline & & $\wedge$ & $\wedge$ \\
& $1983: 2-1994: 2$ & $0.038^{* * *}$ & $\beta$ \\
\hline Denmark krone & $(44)$ & $(0.011)$ & $1.699 * *$ \\
& & & $(0.294)$ \\
Finnish markka & - & - & - \\
Irish pound & $1985: 1-1993: 4$ & 0.013 & $0.013 *$ \\
& $(36)$ & $(0.010)$ & $(0.556)$ \\
Netherlands gulden & $1986: 2-1993: 4$ & $0.015^{* * *}$ & 0.833 \\
& $(30)$ & $(0.005)$ & $(0.386)$ \\
Norway krone & $1986: 1-1994: 2$ & $-0.014 * *$ & $-0.392^{* * *}$ \\
& $(34)$ & $(0.006)$ & $(0.280)$ \\
Spanish peseta & & & - \\
Sweden krona & $1987: 1-1994: 2$ & -0.006 & 0.600 \\
& $(30)$ & $(0.016)$ & $(0.471)$ \\
Swiss franc & $1979: 1-1994: 2$ & $-0.011^{* * *}$ & 1.023 \\
& $(60)$ & $(0.003)$ & $(0.074)$ \\
& & & \\
\hline
\end{tabular}

IV(1) and IV(2) are estimation results with instrumental variables lagged quarterly inflation and lagged long term interest rates, respectively. The sample period pertains to interest rate sample period. Number of observations measured by the number of quarters is in parentheses. Beginning date is the beginning of the interest rate data and ending date is the last observed ex post or forecasted exchange rate minus 5 years ( 20 qtrs) or the last interest rate data, whichever is earlier. The third and fourth columns are the t-test for alpha $=0$ and beta $=1 .{ }^{*},{ }^{* *} .{ }^{* * *}$ indicates coefficient different from null at $10 \%, 5 \%, 1 \%$ significance level respectively. Standard errors are in parentheses. 
Table 3: 3-month Horizon Real Interest Parity Results with ex post CPI Inflation

\begin{tabular}{|c|c|c|c|}
\hline & & $\hat{\alpha}$ & $\hat{\beta}$ \\
\hline Austrian schilling & $\begin{array}{c}1991: 2-2000: 3 \\
\text { (38) }\end{array}$ & $\begin{array}{l}0.016 * * * \\
(0.004)\end{array}$ & $\begin{array}{l}0.017 * * * \\
(0.089)\end{array}$ \\
\hline Australian dollar & $\begin{array}{c}1982: 3-2000: 3 \\
(73)\end{array}$ & $\begin{array}{l}0.066^{* * *} \\
(0.025)\end{array}$ & $\begin{array}{l}-0.641 * * * \\
(0.466)\end{array}$ \\
\hline Belgian frank & $\begin{array}{c}1985: 1-2000: 3 \\
(63)\end{array}$ & $\begin{array}{l}0.787 * * \\
(0.397)\end{array}$ & $\begin{array}{l}0.240 * * \\
(0.374)\end{array}$ \\
\hline Denmark krone & - & & \\
\hline Finnish markka & $\begin{array}{c}1991: 2-1999: 3 \\
(34)\end{array}$ & $\begin{array}{l}0.007 \\
(0.011)\end{array}$ & $\begin{array}{l}0.196 * * * \\
(0.208)\end{array}$ \\
\hline Irish pound & $\begin{array}{c}1991: 2-2000: 3 \\
(38)\end{array}$ & $\begin{array}{l}0.030 * * * \\
(0.009)\end{array}$ & $\begin{array}{l}-0.271 * * * \\
(0.210)\end{array}$ \\
\hline Netherlands gulden & $\begin{array}{c}1991: 2-2000: 3 \\
(38)\end{array}$ & $\begin{array}{l}0.010 \\
(0.020)\end{array}$ & $\begin{array}{l}0.291 \\
(0.642)\end{array}$ \\
\hline Norway krone & $\begin{array}{c}1993: 2-2000: 3 \\
(30)\end{array}$ & $\begin{array}{l}0.013 \\
(0.019)\end{array}$ & $\begin{array}{l}0.278 \\
(0.527)\end{array}$ \\
\hline Spanish peseta & $\begin{array}{c}1991: 4-2000: 3 \\
(36)\end{array}$ & $\begin{array}{l}0.015 \\
(0.016)\end{array}$ & $\begin{array}{l}0.017 * * * \\
(0.342)\end{array}$ \\
\hline Sweden krona & $\begin{array}{c}1991: 2-1993: 4 \\
(11)\end{array}$ & $\begin{array}{l}0.001 \\
(0.008)\end{array}$ & $\begin{array}{l}0.204 * * * \\
(0.164)\end{array}$ \\
\hline Swiss franc & $\begin{array}{c}1991: 2-1993: 4 \\
(11)\end{array}$ & $\begin{array}{l}0.006 \\
(0.010)\end{array}$ & $\begin{array}{l}0.023 * * * \\
(0.122)\end{array}$ \\
\hline
\end{tabular}

Ex post CPI inflation is calculated as the percentage change between the 20 quarters ahead consumer price index and the current consumer price index. The sample period pertains to interest rate sample period. Number of observations measured by the number of quarters is in parentheses. Beginning date is the beginning of the interest rate data and ending date is the last observed ex post or forecasted exchange rate minus 1 quarter or the last interest rate data, whichever is earlier. The third and fourth columns are the $\mathrm{t}$-test for alpha $=0$ and beta $=1 .{ }^{*},{ }^{* *} .{ }^{* * *}$ indicates coefficient different from null at 10\%, 5\%, 1\% significance level respectively. For Belgium, 6month real interest rates are used. Standard errors are in parentheses. 
Table 4: 5-Year Horizon Real Interest Parity Results with ex post CPI Inflation

\begin{tabular}{|c|c|c|c|}
\hline & & $\hat{\alpha}$ & $\hat{\beta}$ \\
\hline Denmark krone & $\operatorname{IV}(1)$ & $0.027 * * *(0.007)$ & $0.186 * * *(0.131)$ \\
\hline 1991:1 - 1996:3(23) & $\operatorname{IV}(2)$ & $0.008(0.006)$ & $0.458 * * *(0.129)$ \\
\hline Finnish markka & - & - & - \\
\hline Irish pound & $\operatorname{IV}(1)$ & $0.056 * * *(0.016)$ & $-0.241 * * *(0.227)$ \\
\hline $1985: 2-1996: 3(46)$ & $\operatorname{IV}(2)$ & $0.023 * * *(0.006)$ & $0.243 * * *(0.093)$ \\
\hline Netherlands gulden & $\operatorname{IV}(1)$ & $0.042 * *(0.021)$ & $-0.043 * *(0.434)$ \\
\hline $1986: 2-1996: 3(42)$ & $\operatorname{IV}(2)$ & $-0.010(0.010)$ & $1.051(0.174)$ \\
\hline Norway krone & $\operatorname{IV}(1)$ & $0.066^{* *}(0.029)$ & $-0.374 * * *(0.362)$ \\
\hline $1986: 2-1996: 3(42)$ & $\operatorname{IV}(2)$ & $0.015 * *(0.007)$ & $0.342 * * *(0.104)$ \\
\hline Spanish peseta & - & - & - \\
\hline Sweden krona & $\operatorname{IV}(1)$ & $0.043 * * *(0.014)$ & $-0.066 * * *(0.220)$ \\
\hline $1990: 3-1996: 3(25)$ & $\operatorname{IV}(2)$ & $0.093(0.071)$ & $-0.686 *(0.871)$ \\
\hline Swiss franc & $\operatorname{IV}(1)$ & $0.104(0.082)$ & $-1.750(2.990)$ \\
\hline 1979:1 - 1996:3(71) & $\operatorname{IV}(2)$ & $0.106(0.091)$ & $-2.001(3.761)$ \\
\hline
\end{tabular}

IV(1) and IV(2) are estimation results with instrumental variables lagged quarterly inflation and lagged long term interest rates, respectively. Ex post CPI inflation is calculated as the percentage change between the 20 quarters ahead consumer price index and the current consumer price index. The sample period pertains to interest rate sample period. Number of observations measured by the number of quarters is in parentheses. Beginning date is the beginning of the interest rate data and ending date is the last observed ex post or forecasted exchange rate minus 5 years ( 20 qtrs) or the last interest rate data, whichever is earlier. The third and fourth columns are

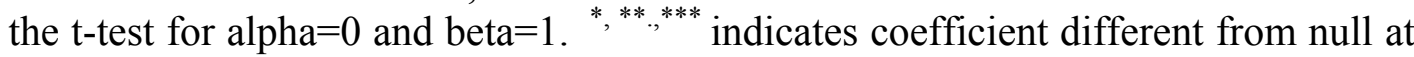
$10 \%, 5 \%, 1 \%$ significance level respectively. Standard errors are in parentheses. 
Table 5: 5-Year Horizon Real Interest Parity Results with ex post PPI Inflation

\begin{tabular}{|c|c|c|c|}
\hline & & $\hat{\alpha}$ & $\hat{\beta}$ \\
\hline Denmark krone & IV $(1)$ & $0.075(0.075)$ & $-0.287(1.425)$ \\
\hline 1991:1 - 1996:3(23) & $\operatorname{IV}(2)$ & $0.021 * * *(0.007)$ & $0.409 * * *(0.143)$ \\
\hline Finnish markka & - & - & - \\
\hline Irish pound & $\operatorname{IV}(1)$ & $0.040(0.025)$ & $0.267 * *(0.298)$ \\
\hline $1985: 2-1995: 3(42)$ & $\operatorname{IV}(2)$ & $0.037 * * *(0.013)$ & $0.228 * * *(0.180)$ \\
\hline Netherlands gulden & $\operatorname{IV}(1)$ & $-0.031(0.080)$ & $1.639(1.051)$ \\
\hline $1986: 2-1996: 4(42)$ & $\operatorname{IV}(2)$ & $-0.004(0.047)$ & $1.175(0.756)$ \\
\hline Norway krone & $\operatorname{IV}(1)$ & $0.019(0.062)$ & $0.575(0.775)$ \\
\hline $1986: 2-1996: 2(41)$ & $\operatorname{IV}(2)$ & $0.016(0.039)$ & $0.521(0.509)$ \\
\hline Spanish peseta & - & - & - \\
\hline Sweden krona & $\operatorname{IV}(1)$ & $0.073 * * *(0.014)$ & $-0.303 * * *(0.202)$ \\
\hline $1990: 3-1996: 3(25)$ & $\operatorname{IV}(2)$ & $0.150(0.187)$ & $-1.426(2.591)$ \\
\hline Swiss franc & $\operatorname{IV}(1)$ & $0.120 * *(0.050)$ & $-0.610(1.321)$ \\
\hline 1979:1 - 1996:3(71) & $\operatorname{IV}(2)$ & $-0.033(0.119)$ & $2.405(2.978)$ \\
\hline
\end{tabular}

IV(1) and IV(2) are estimation results with instrumental variables lagged quarterly inflation and lagged long term interest rates, respectively. Ex post PPI inflation is calculated as the percentage change between the 20 quarters ahead producer price index and the current producer price index. The sample period pertains to interest rate sample period. Number of observations measured by the number of quarters is in parentheses. Beginning date is the beginning of the interest rate data and ending date is the last observed ex post or forecasted exchange rate minus 5 years (20 qtrs) or the last interest rate data, whichever is earlier. The third and fourth columns are the t-test for alpha $=0$ and beta $=1 .^{*}{ }^{* *} .{ }^{* * *}$ indicates coefficient different from null at $10 \%, 5 \%, 1 \%$ significance level respectively. Standard errors are in parentheses. 
Table 6: 5-Year Horizon Real Interest Parity Results with Forecasted CPI Inflation

\begin{tabular}{|c|c|c|c|}
\hline & & $\hat{\alpha}$ & $\hat{\beta}$ \\
\hline Denmark krone & $\operatorname{IV}(1)$ & $0.055 * * *(0.011)$ & $0.092 * * *(0.180)$ \\
\hline 1991:1 - 1998:1(29) & $\operatorname{IV}(2)$ & $0.033 * * *(0.008)$ & $0.378 * * *(0.101)$ \\
\hline Finnish markka & IV $(1)$ & $-0.046(0.096)$ & $1.092(1.023)$ \\
\hline 1991:4 - 1998:1(26) & $\operatorname{IV}(2)$ & $0.011(0.008)$ & $0.517 * * *(0.072)$ \\
\hline Irish pound & IV $(1)$ & $0.051 *(0.028)$ & $0.121 * * *(0.180)$ \\
\hline $1985: 2-1998: 2(61)$ & $\operatorname{IV}(2)$ & $0.028 *(0.015)$ & $0.284 * * *(0.098)$ \\
\hline Netherlands gulden & $\operatorname{IV}(1)$ & $0.103 * * *(0.022)$ & $-0.083 * * *(0.048)$ \\
\hline $1986: 2-1994: 3(34)$ & $\operatorname{IV}(2)$ & $0.076 * * *(0.004)$ & $-0.012 * * *(0.006)$ \\
\hline Norway krone & $\operatorname{IV}(1)$ & $0.093 *(0.050)$ & $-0.178 * * *(0.374)$ \\
\hline 1986:1 - 1998:1(57) & $\operatorname{IV}(2)$ & $0.026 * * *(0.007)$ & $0.385 * * *(0.057)$ \\
\hline Spanish peseta & $\operatorname{IV}(1)$ & $0.124 *(0.063)$ & $-0.526 * * *(0.505)$ \\
\hline 1992:1 - 1998:1(25) & $\operatorname{IV}(2)$ & $0.046 * * *(0.806)$ & $0.105 * * *(0.067)$ \\
\hline Sweden krona & $\operatorname{IV}(1)$ & $-0.011(0.015)$ & $0.658 * * *(0.124)$ \\
\hline 1987:2 - 1998:2(45) & $\operatorname{IV}(2)$ & $0.021 * *(0.008)$ & $0.401 * * *(0.055)$ \\
\hline Swiss franc & $\operatorname{IV}(1)$ & $-0.071(0.141)$ & $3.105(2.523)$ \\
\hline 1973:1 - 1998:1(101) & $\operatorname{IV}(2)$ & $-0.021(0.044)$ & $2.048(0.877)$ \\
\hline
\end{tabular}

IV(1) and IV(2) are estimation results with instrumental variables lagged quarterly inflation and lagged long term interest rates, respectively. Forecasted CPI inflation is calculated by estimating ARIMA on inflation rates, as log differences, and iterated up to levels, then calculated inflation using exact formula. The sample period pertains to interest rate sample period. Number of observations measured by the number of quarters is in parentheses. Beginning date is the beginning of the interest rate data and ending date is the last observed ex post or forecasted exchange rate minus 5 years ( 20 qtrs) or the last interest rate data, whichever is earlier. The third and fourth columns are the t-test for alpha $=0$ and beta $=1 .{ }^{*},{ }^{* *} .{ }^{* * *}$ indicates coefficient different from null at $10 \%, 5 \%, 1 \%$ significance level respectively. Standard errors are in parentheses. 
Table 7: 5-Year Horizon Real Interest Parity Results with Forecasted PPI Inflation

\begin{tabular}{|c|c|c|c|}
\hline & & $\hat{\wedge}$ & $\hat{\beta}$ \\
\hline Denmark krone & $\operatorname{IV}(1)$ & $0.217(0.631)$ & $-3.753(13.900)$ \\
\hline 1991:1 - 1998:1(29) & $\operatorname{IV}(2)$ & $0.020 * * *(0.007)$ & $0.362 * * *(0.109)$ \\
\hline Finnish markka & $\operatorname{IV}(1)$ & $0.013(0.010)$ & $0.387 * * *(0.156)$ \\
\hline 1991:4 - 1998:1(26) & $\operatorname{IV}(2)$ & $0.014 *(0.008)$ & $0.496 * * *(0.114)$ \\
\hline Irish pound & $\operatorname{IV}(1)$ & $0.021(0.019)$ & $0.449 * *(0.280)$ \\
\hline $1985: 2-1998: 2(53)$ & $\operatorname{IV}(2)$ & $0.031 * * *(0.007)$ & $0.258 * * *(0.090)$ \\
\hline Netherlands gulden & $\operatorname{IV}(1)$ & $0.014(0.027)$ & $0.740(0.474)$ \\
\hline 1986:2 - 1998:1(48) & $\operatorname{IV}(2)$ & $-0.006(0.015)$ & $1.026(0.208)$ \\
\hline Norway krone & $\operatorname{IV}(1)$ & $0.044 * *(0.017)$ & $0.163 * * *(0.236)$ \\
\hline 1986:1 - 1998:1(48) & $\operatorname{IV}(2)$ & $0.023 * * *(0.005)$ & $0.377 * * *(0.065)$ \\
\hline Spanish peseta & $\operatorname{IV}(1)$ & $0.020 * *(0.009)$ & $0.305 * * *(0.143)$ \\
\hline 1992:1 - 1998:1(25) & $\operatorname{IV}(2)$ & $0.035 * * *(0.004)$ & $0.085 * * *(0.073)$ \\
\hline Sweden krona & $\operatorname{IV}(1)$ & $0.001(0.024)$ & $0.701(0.363)$ \\
\hline $1987: 2-1998: 2(45)$ & $\operatorname{IV}(2)$ & $0.024 * * *(0.006)$ & $0.381 * * *(0.065)$ \\
\hline Swiss franc & $\operatorname{IV}(1)$ & $0.138(0.138)$ & $-0.712(1.350)$ \\
\hline $1985: 2-1998: 1(52)$ & $\operatorname{IV}(2)$ & $-0.162 * *(0.076)$ & $2.105(0.736)$ \\
\hline
\end{tabular}

IV(1) and IV(2) are estimation results with instrumental variables lagged quarterly inflation and lagged long term interest rates, respectively. Forecasted PPI inflation is calculated by estimating ARIMA on inflation rates, as log differences, and iterated up to levels, then calculated inflation using exact formula. The sample period pertains to interest rate sample period. Number of observations measured by the number of quarters is in parentheses. Beginning date is the beginning of the interest rate data and ending date is the last observed ex post or forecasted exchange rate minus 5 yrs ( 20 qtrs) or the last interest rate data, whichever is earlier. The third and fourth columns are the t-test for alpha $=0$ and beta $=1 .{ }^{*},{ }^{* *} .{ }^{* * *}$ indicates coefficient different from null at $10 \%, 5 \%, 1 \%$ significance level respectively. Standard errors are in parentheses. 
Table 8: Comparable Regression with a sample of G-5 countries

\begin{tabular}{|c|c|c|c|}
\hline & & $\hat{\alpha}=0$ & $\hat{\beta}=1$ \\
\hline \multicolumn{4}{|c|}{ Panel 1: 5-Year Horizon Uncovered Interest Parity Results with Ex Post Exchange Rates } \\
\hline $\begin{array}{l}\text { German mark } \\
\text { 1979:1-1993:4(60) }\end{array}$ & & $0.005(0.013)$ & $1.043(0.522)$ \\
\hline $\begin{array}{l}\text { UK pound } \\
\text { 1979:1-1996:3(71) }\end{array}$ & & $0.005(0.012)$ & $0.993(0.403)$ \\
\hline \multicolumn{4}{|c|}{ Panel 2: 5-Year Horizon Real Interest Parity Results with Ex Post CPI Inflation } \\
\hline German mark & IV(1) & $0.154(0.192)$ & $-1.709(3.321)$ \\
\hline 1979:1-1996:3(71) & $\operatorname{IV}(2)$ & $-0.020(0.047)$ & $1.458(0.955)$ \\
\hline UK pound & IV $(1)$ & $-0.035(0.072)$ & $1.477(1.146)$ \\
\hline 1979:1-1996:3(71) & $\operatorname{IV}(2)$ & $0.003(0.023)$ & $0.820(0.321)$ \\
\hline
\end{tabular}

IV(1) and IV(2) are estimation results with instrumental variables lagged quarterly inflation and lagged long term interest rates, respectively. Ex post CPI inflation is calculated as the percentage change between the 20 quarters ahead consumer price index and the current consumer price index. The sample period pertains to interest rate sample period. Number of observations measured by the number of quarters is in parentheses. Beginning date is the beginning of the interest rate data and ending date is the last observed ex post or forecasted exchange rate minus 5 years ( 20 qtrs) or the last interest rate data, whichever is earlier. The third and fourth columns are the t-test for alpha $=0$ and beta $=1 .{ }^{*},{ }^{* *} .{ }^{* * *}$ indicates coefficient different from null at $10 \%, 5 \%, 1 \%$ significance level respectively. Standard errors are in parentheses. 